\title{
EFFECT OF LAG-SCREW POSITIONS ON FIXATION FAILURE IN PATIENTS WITH INTERTROCHANTERIC FRACTURES OF THE FEMUR
}

\author{
By
Mahmoud Ali Mohammed Sayed Ahmed, Kamal Abd Al-Rhman Abd El-Hafez and Mohammed Moawad Abd El-Motlb

Department of orthopedic surgery, Faculty of Medicine, Al-Azhar University

Corresponding author: Mahmoud Ali Mohammed Sayed Ahmed

Mobile: 01285225435, E-mail: dr.mahmoudali873@gmail.com

\begin{abstract}
Background: The dynamic hip screw (DHS) is widely used in treating the intertrochanteric fractures of the femur in old patients. The positions of the lag screw in the femoral neck and the distance between the tip of the lag screw and the apex of the femoral head are very important for the procedure success.

Objective: To assess lag-screw positions rule on failure of fixation intertrochanteric femur fractures.

Patients and Methods: This was a case presentation study contained twenty patients aged $\geq 50$ with unstable types of intertrochanteric fractures, and had been subjected to dynamic hip screws.

Results: This study included (13) females and (7) males whose ages ranged between (58) to (86) years, Failure of fixation seen in 15 cases $(75 \%)$ of all cases and union seen only in 5 cases $(25 \%)$. The mean tip apex distance (TAD) was significantly longer when with fixation failure $(\mathrm{p}=0.002)$. Relation of Location of Lag Screw to fixation failure had no statistically significant difference. Tip apex distance(TAD)was significantly longer among the studied cases with inferior-centeral (I-C) location of lag screw as compared with centeral-centeral $(\mathrm{C}-\mathrm{C})$ location of lag screw $(\mathrm{p}=0.006)$.

Conclusion: The Tip apex distance (TAD) wasan easy effective way which was very important to determine the location of the screw. Regardless place of the guide-pin was placed as long as the aimed position results in a tip-apex distance of greater than twenty-five millimeters. So, it was recommended to reconsider the guide pin reduction and redirection.
\end{abstract}

Keywords: Femur Intertrochanteric fractures, Tip Apex distance, Dynamic hip screw, Fixation failure.

\section{INTRODUCTION}

Femur intertrochanteric fractures have been managed by dynamic hip screw (DHS) widely in old patients with high success rate and low problems rate especially when types of fracture are diagnosed well and DHS of lag screw is correctly placed (Rudolf et al., 2015 and Sinan et al., 2015).
The lag screw has two preferred placing positions which may be placed superior to the other; either the lag screw is placed in the central-central area or in the inferior 1/3-central area (Koun et al., 2016). The ways of failure of fixation are different according to the lag screw place in the head of femur. Baumgaertner (1995) calculated the tip-apex distance 
(TAD) concept to mark the place of lag screw in the head of femur (Zehir et al., 2015).

This calculation, measured in millimeters, is the total value distance from apical head of femur to lag screw tip in X-ray both lateral and AP views and this is done after holding radiographic magnification. Shallow position of lag screw is not distinguished from peripheral lag screw mal-positioning. It is only differentiated by the actual distance from apical head of femur to the lag screw tip (Li et al., 2015).

Baumgaertner (1995) proved that the strongest measurement of screw site was TAD (though not the only) independent lag screw cut-out prediction. TAD should be $<25 \mathrm{~mm}$ to decrease the risk of lag screw cutout (Mardani-Kivi et al., 2015).

This study aimed to assess lag-screw positions rule on unsuccessful fixation in femur intertrochanteric fractures patients.

\section{PATIENTS AND METHODS}

This current study was case series study done between January 2019 and November 2019 on twenty patients with age $\geq 50$ males and females with intertrochanteric fractures including unstable sorts whom were treated with dynamic hip screws.

Patients were evaluated before operations regarding to: (history taking, clinical assessment, lab investigations and hip radiographic were taken in the antero - posterior and in lateral views). Patients with active decontaminated surgical site, not suited for surgical approach, poly- traumatized or pathological fractures were not included in this study. All patients were assented about the surgery, possible complications, risks and follow up plan.

X-ray was a rule immediately after operations, antero-posterior pelvis view and lateral view of operated pelvis. The urgent postoperative images were evaluated for varus or valgus angulation on antero-posterior radiograph and apex anterior or posterior angulation on the lateral radiograph. The reduction was then classified as acceptable, good or poor. For a reduction to be classified as acceptable, ordinary or slight valgus arrangement $(<5$ degrees) on the antero-posterior radiograph, less than ten degrees of angulation on the lateral radiograph, and close to $5 \mathrm{~mm}$ of removal of any piece. Satisfactory; a reduction needed to meet one rule of a good reduction as for either arrangement or displacement, yet not both. A poor reduction met neither criterion.

Statistical Methods: The collected data were coded then entered and analyzed using the SPSS version 22 (Statistical package for the social sciences22). Descriptive statistics were done for categorical variables by frequency and percentage, and for numerical variables in the form of mean and standard deviation (mean $\pm \mathrm{SD}$ ). Suitable statistical tests of significance were used (Independent Sample t-test for two unrelated samples, Chi-Square $(\chi 2)$ test for categorical data). $\mathrm{P}$-values equal to or less than 0.05 were considered statistically significant. Simple graphs were used to illustrate some information. 


\section{RESULTS}

This present study included twenty (20) patients distributed as (7) males and (13) females with age ranged from 58 to 86 years old, and an average age of 73.25
士7.39. Among our studied population; fixation failure occurred in 15 cases $(75 \%)$ of the collected cases and union occurred in 5 cases $(25 \%)$ (Chart $\mathbf{1})$.

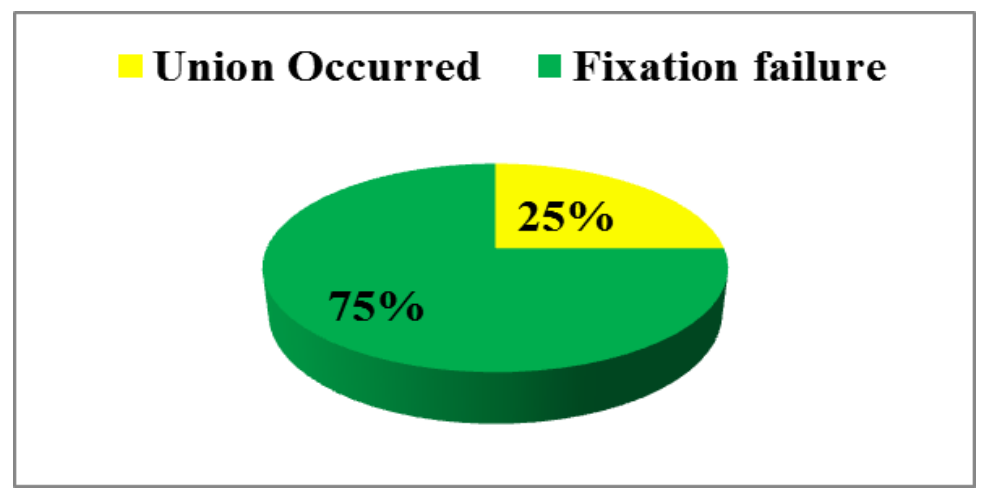

\section{Chart (1): Frequency of Fixation failure among studied population}

In 11 cases $(73.3 \%)$, failure was attributable to cut-out of the lag screw at the supero-lateral edge of the femoral head in 2 cases $(13.3 \%)$, to penetration of the lag screw into the acetabulum in 1 case $(6.7 \%)$, and marked collapse at the fracture site and in 1 case $(6.7 \%)$; failure was attributable to pulling out of the plate (Chart 2).

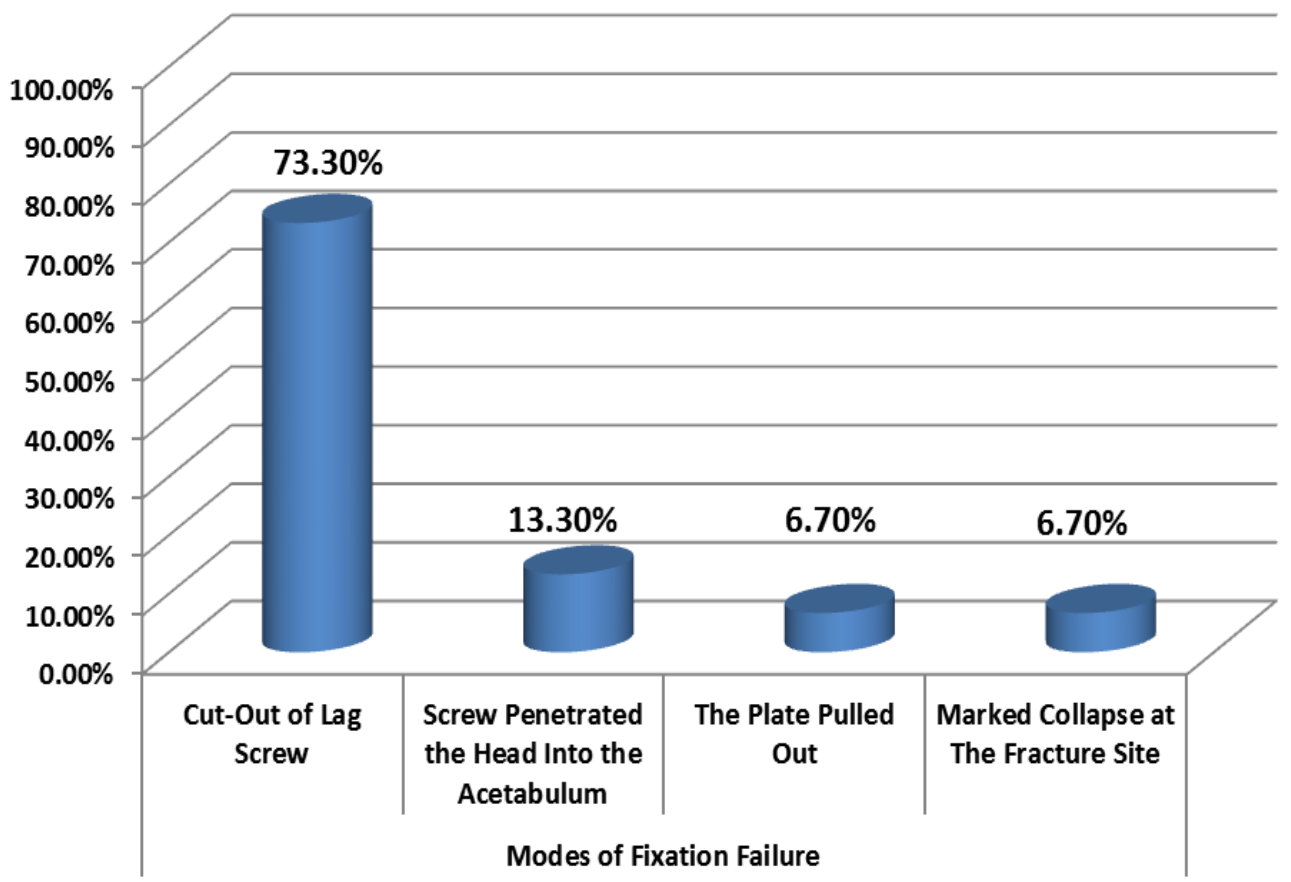

Chart (2): Frequency of Modes of Fixation Failure 
In the present study, fixation failure was not related to patient's age; mean age was (72.80 vs. 73.40) in patients with successful healing and fixation failure respectively. Fixation failure was more common in females than males. However; difference between the two groups was statistically non-significant $(\mathrm{p}$ value $=$ 0.406).In the failure group, the females were $60.0 \%$, and the males were $40.0 \%$. In the union group, the females were $80.0 \%$ and the males were $20.0 \%$.

Fractures were classified according to Kyle modification of Boyd and Griffin classification. Out of the 10 cases that were classified as type II, 7 cases of them had fixation failure. Out of the 7 cases that were classified as type III, 7 cases of them had fixation failure. Out of the 3 cases that were classified as type IV, 3 cases of them had fixation failure. There was a direct relationship between the fracture classification and the probability of fixation failure.
However; the difference between the three groups was statistically insignificant.

The mean tip apex distance (TAD) was 23.45 millimeters (range, 13 to $38 \mathrm{~mm}$ ) for the 20 cases. TAD was significantly higher among the studied cases with fixation failure. In the 15 cases in which fixation failure occurred, the mean TAD was 26.80 millimeters (range, 18 to $49 \mathrm{~mm}$ ). In the 5 cases of fracture union, the mean TAD was 26 millimeters (range, 12 to $37 \mathrm{~mm}$ ). The results were statistically significant $(\mathrm{p}$ value $=0.002)$. There was a direct relationship between an increased tip apex distance (TAD) and an increased risk of fixation failure. All the studied cases with union had a tip apex distance (TAD) $<25$ millimeters. Out of the 15 cases with fixation failure; nine cases had a tip apex distance (TAD) $\geq 25$ millimeters; and 6 cases had a TAD $<25$ millimeters. The difference between the two groups was statistically significant $(\mathrm{p}$ value $=$ 0.030) (Table 1).

Table (1): Association between complications and other studied variables.

\begin{tabular}{|c|c|c|c|}
\hline $\begin{array}{l}\text { Complications } \\
\text { Variables }\end{array}$ & $\begin{array}{l}\text { Union Occurred } \\
\qquad \mathrm{N}=5\end{array}$ & $\begin{array}{l}\text { Fixation Failure } \\
\qquad \mathrm{N}=15\end{array}$ & p-value \\
\hline \multicolumn{4}{|l|}{ Age (years) } \\
\hline Mean \pm SD & $72.80 \pm 9.20$ & $73.40 \pm 7.05$ & 0.880 \\
\hline \multicolumn{4}{|l|}{ Sex N (\%) } \\
\hline Male; $(\mathrm{N}=7)$ & $1(20.0)$ & $6(40.0)$ & 0.417 \\
\hline Female; $(\mathrm{N}=13)$ & $4(80.0)$ & $9(60.00$ & \\
\hline \multicolumn{4}{|c|}{ Fracture Classification N (\%) } \\
\hline II part Fracture; $(\mathrm{N}=10)$ & $3(60.0)$ & $7(46.7)$ & 0.714 \\
\hline III part Fracture; $(\mathrm{N}=7)$ & $1(20.0)$ & $6(40.0)$ & \\
\hline IV part Fracture; $(\mathrm{N}=3)$ & $1(20.0)$ & $2(13.3)$ & \\
\hline \multicolumn{4}{|c|}{ Mean Tip-Apex Distance (TAD) (mm) } \\
\hline Mean \pm SD & $15.80 \pm 1.92$ & $26.00 \pm 6.19$ & 0.002 \\
\hline \multicolumn{4}{|c|}{ Tip-Apex Distance (TAD) mm N (\%) } \\
\hline$<25 ;(\mathrm{N}=11)$ & $5(45.5)$ & $6(54.5)$ & 0.020 \\
\hline$\geq 25 \mathrm{~mm} ;(\mathrm{N}=9)$ & $0(0.00)$ & $9(100.0)$ & \\
\hline \multicolumn{4}{|c|}{ Location of Lag Screw N (\%) } \\
\hline $\mathrm{C}-\mathrm{C} ;(\mathrm{N}=16)$ & $4(80.0)$ & $12(80.0)$ & 1 \\
\hline $\mathrm{I}-\mathrm{C} ;(\mathrm{N}=4)$ & $1(20.0)$ & $3(20.0)$ & \\
\hline
\end{tabular}


All the studied cases with union had central-central area location of lag screw, while in fixation failure cases, 11 cases had central-central area location of lag screw and only 4 cases had inferior $1 / 3-$ central area location of lag screw with no statistically significant difference between both groups.

Cut-Out of Lag Screw was significantly more common among studied patients with $\mathrm{C}-\mathrm{C}$ location of lag screw $(56.3 \%$ vs. $0 \%)$ in C-C and I-C respectively, the same finding was present with screw penetration of the head into the acetabulum ( $12.5 \%$ vs. $0 \%)$ in C-C and I-
$\mathrm{C}$ respectively. On the other hand pulling out of the plate was more common with IC location of lag screw (25\% vs. $6.30 \%$ ) in $\mathrm{I}-\mathrm{C}$ and $\mathrm{C}-\mathrm{C}$ respectively as well as marked collapse at the fracture site $(50 \%$ vs. 9\%) in I-C and C-C respectively. TAD was significantly longer among the studied cases with I-C location of lag screw as compared with C-C location of lag screw. In the four cases I-C group; the mean TAD was 32.50 millimeters while in the 16 cases $\mathrm{C}-\mathrm{C}$ group; the mean TAD was 21.18 millimeters. The results were statistically significant $(\mathrm{p}$ value $=0.006$ ) (Table 2).

Table (2): Relation of Location of Lag Screw to modes of fixation failure and tipapex distance (TAD) $\mathrm{mm}$

\begin{tabular}{|c|c|c|c|}
\hline \multirow{2}{*}{$\begin{array}{l}\text { Location of Lag Screw } \\
\text { Modes of Fixation Failure; N (\%) }\end{array}$} & & & \multirow[b]{2}{*}{ p-value* } \\
\hline & $\begin{array}{c}\mathrm{C}-\mathrm{C} \\
\mathrm{N}=12\end{array}$ & $\begin{array}{c}I-C \\
N=3\end{array}$ & \\
\hline Cut-Out of Lag Screw & $9(75.0)$ & $0(0.00)$ & \multirow{4}{*}{$<0.008 *$} \\
\hline $\begin{array}{l}\text { Screw Penetrated the Head Into the } \\
\text { Acetabulum }\end{array}$ & $2(16.67)$ & $0(0.00)$ & \\
\hline The Plate Pulled Out & $1(8.33)$ & $1(33.33)$ & \\
\hline Marked Collapse at The Fracture Site & $0(0.00)$ & $2(66.67)$ & \\
\hline \multicolumn{4}{|l|}{ Mean Tip-Apex Distance (TAD); (mm) } \\
\hline Mean \pm SD & $21.187 \pm 5.6$ & $32.50 \pm 4.4$ & $<0.007 *$ \\
\hline
\end{tabular}

\section{DISCUSSION}

About half of all fractures of hip are intertrochanteric. There are different tools that might be utilized for unsuccessful fixation. The DHS is a screw that permits controlling dynamic femoral head sliding and is utilized to fix both the femoral head and the tool to femur shaft. The dynamic pressure permits the weight-bearing worries for femur stabilizing with the goal that it might experience remodeling and allow appropriate healing of fracture (Mardani-Kivi et al., 2013).

Despite the fact that DHS fixation tools has been the highest quality level treatment for stable intertrochanteric fractures (KHAN et al., 2010), there are numerous problems revealed for unstable fractures (3-26\%) (Aicale andMaffulli, 2018).

In the current study, the mean age of patients with successful fracture healing was younger than those with unsuccessful; anyway the impact age on unsuccessful fixation was non-significant. Our results in regards to age was with Davis and his colleges demonstrated that $98 \%$ of the patients in whom the fixation was unsuccessful were $\geq$ sixty years of age and $2 \%$ were < sixty years of age. Hip fractures incidence is more common in 
women 2-3 times than in men (Dhanwal et al., 2010). Due to their lower bone mass, quick bone loss after menopause and more serious danger of falls, ladies are two to eight times more to sustain hip fractures than men (Reindl, 2015). These findings of our current study demonstrated that the classification of fracture was related directly to unsuccessful fixation probability. In any way; the three groups' difference was insignificant. In the current study, with regard to the Bit, the mean tipapex length was 23.45 millimeters (extend, 13 to $38 \mathrm{~mm}$ ) for the twenty patients. TAD was higher significantly between the examined cases with unsuccessful fixation. In the fifteen cases with unsuccessful fixation, TAD mean was 26.80 millimeters (extend, 18 to $49 \mathrm{~mm})$. In the five cases of healed fractures, TAD mean was 26 millimeters (extend, 12 to $37 \mathrm{~mm}$ ). The results were significant.

Additionally, in a study intended to survey the utilization of TAD in predicting screw cut after fixation by DHS in an Asian people (Mardani-Kivi et al., 2013). The TAD average was $36.9 \mathrm{~mm}$ (go: $23.1-58.7 \mathrm{~mm}$ ) in the group of screw cut out, contrasted with $21.7 \mathrm{~mm}$ (extend: $6.2-41.8 \mathrm{~mm}$ ) in those without screw cut out.

The danger of screw cut out is related to TAD increasing (Chua et al., 2011). In our current study; all the examined cases with healing had a TAD $<25$ millimeters. Out of the fifteen cases with unsuccessful fixation; only 9 cases had a TAD $\geq 25$ millimeters; and only six patients had a TAD $<25$ millimeters. The contrast between the two groups was significant.
At the point when Touch was 20-24 $\mathrm{mm}$, the danger of screw cut out was $2.9 \%$. There was an expanded danger of screw cut out of $20.0 \%, 30.8 \%$, half and $100 \%$ when the Smidgen extend expanded from $25-29 \mathrm{~mm}, 30-34 \mathrm{~mm}, 35-44 \mathrm{~mm}$ and $>45 \mathrm{~mm}$ separately (Dhanwal et al., 2010).

The twisting burden is higher in the vertical than in the horizontal bearing (about $17^{\circ}$ downwards and along the side). The lag screw in this manner step by step relocates into the upper region of the femoral head. Thus, a force creates and the femoral head turns downwards and medially (Chua et al., 2011). In this manner, the lag screw moves upwards and along the side, and results in cut-out superolaterally. At the point when a lag screw is set in the second rate some portion of the femoral head in the frontal plane, a force creates between the resultant power and the lag screw head. The femoral head turns upwards and along the side, and the lag screw uproots downwards and medially. The separation between the lag screw and the superolateral edge of the femoral head increases, in this manner the chance of cut-out will decrease .At the point when the lag screw is put poorly in the frontal plane, the femoral head turns upwards and horizontally and the lag screw skims distally along the barrel of the side-plate. Correspondingly, the lag screw dislodges downwards and medially in the femoral head. When the lag screw coasts and sticks the barrel of the side-plate, the descending burden powers the screw head and enters into the hip bone socket. On the off chance that the lag screw doesn't infiltrate into the hip bone socket, dynamic further coasting of the lag screw 
can create malunion or nonunion of fracture portions. In addition, a huge bowing burden may cause breakage of the side-plate screws and plate extricating. The frequency of cut-out of the lag screw of the DHS is accounted for to be 0 to 17\% (Dhanwal et al., 2010).

The present device and the relation between lag screw cut out and its position isn't well cleared (Mardani-Kivi et al., 2013). So, lag screw position in the central or inferior $1 / 3$-central region is achievable as a rule.

In old patients with unstable femur intertrochanteric fractures, various places of the may prompt various ways of unsuccessful fixation. In this study, Lag screw cut-out was increasing significantly between examined patients with C-C lag screw position $(56.3 \%$ versus $0 \%)$ especially in C-C and I-C. The head of femur constantly floats downwards and the lag screw moves upwards. A medial and downward force affecting on the femoral head quickens the lag screw cutout. Lag screw positioning in the lower portion of femur head may prohibit such a problem (Chua et al., 2011).

TAD was longer between the examined cases significantly with I-C position of lag screw as contrasted to C-C lag screw position. In I-C group 4 cases; the mean TAD was 32.50 millimeters while in $\mathrm{C}-\mathrm{C}$ group remaining 16 cases; the mean value was 21.18 millimeters which was a statistically significant results. Comparable results were detected by $W u$ et al., the TAD was shorter significantly in (C-C) group than in (I-C) group patients (19 versus $30 \mathrm{~mm}$ ). It was utilized to anticipate the frequency of cut-out of the lag screw and its value was $25 \mathrm{~mm}$ (Dhanwal et al., 2010).

\section{CONCLUSION}

There was a direct relationship between the fracture classification and the probability of fixation failure. The risk of fixation failure was higher in unstable fracture patterns. The probability of fixation failure was significantly more common in females than males. The tipapex distance (TAD) was a simple reproducible method that was very helpful to describe the location of the screw. The routine intra-operative estimation of the tip-apex distance can increase the surgeon's awareness of the probability of cut-out of the screw and can help to guide operative decision-making. Regardless of the zone in which the guide-pin was placed, if the proposed position results in a TAD of greater than 25 millimeters, then it is recommended to reconsider the reduction and redirection of the guide-pin.

\section{REFERENCES}

1. Aicale, R., andMaffulli, N. (2018): Greater rate of cephalic screw mobilisation following proximal femoral nailing in hip fractures with a tip-apex distance (TAD) and a calcar referenced TAD greater than $25 \mathrm{~mm}$. Journal of Orthopaedic Surgery and Research, 13(1): 106-110.

2. Baumgaertner, M., Curtin, S., Lindskog, D.andKeggi, J. M. (1995): The value of the tip-apex distance in predicting failure of fixation of. $\mathrm{J}$ Bone Joint Surg Am., 77: 1058-1064.

3. Chua, Y. P., Kwan, M. K., Ng, W. M. and Saw, A. (2011): Use of the Tip-apex distance in predicting dynamic hip screw cut out in intertrochanteric fracture of the 
femur in Asian population. Malaysian Orthopaedic Journal, 5(2): 24-27.

4. Dhanwal, D. K., Cooper, C.and Dennison, E. M. (2010): Geographic variation in osteoporotic hip fracture incidence: the growing importance of Asian influences in coming decades. Journal of Osteoporosis,26(1):53-60

5. Haidukewych, G. J. (2009): Intertrochanteric fractures: ten tips to improve results. JBJS, 91(3):712-719.

6. KHAN, N. U., Khan, M. A., ASKAR, Z., Hakeem, A., AHMED, I., Ullah, F., andDurrani, Z. (2010): Intertrochanteric Fracture of Femur. The Professional Medical Journal, 17(02): 328-333.

7. Li, X., Zhang, L., Hou, Z., Meng, Z., Chen, W., Wang, P.and Zhang, Y. (2015): Distal locked and unlocked nailing for perthrochanteric fractures-a prospective comparative randomized study. International Orthopaedics, 39(8): 1645-1652.

8. Mardani-Kivi, M., Mirbolook, A., Jahromi, S. K. and Rad, M. R. (2013): Fixation of intertrochanteric fractures: dynamic hip screw versus locking compression plate. Trauma Monthly, 18(2): 67-71.

9. Reindl, R., Harvey, E. J., Berry, G. K., andRahme, E. (2015): Intramedullary versus extramedullary fixation for unstable intertrochanteric fractures: a prospective randomized controlled trial. JBJS, 97(23): 1905-1912.

10. Yamauchi, K., Naofumi, M., Sumida, H., Fukuta, S. and Hori, H. (2016): Comparison of morphological features in the femur between femoral neck fractures and femoral intertrochanteric fractures. Surgical and Radiologic Anatomy, 38(7): 775-780.

11. Zehir, S., Zehir, R., Zehir, S., Azboy, İ.andHaykir, N. (2015): Proximal femoral nail antirotation against dynamic hip screw for unstable trochanteric fractures; a prospective randomized comparison. European Journal of Trauma and Emergency Surgery, 41(4): 393-400. 


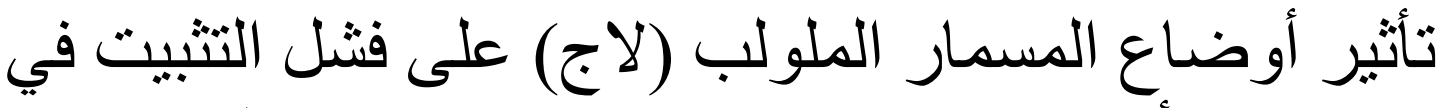

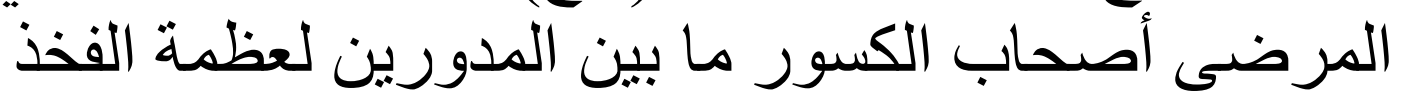
محمود علي محمد سيد أحمد، كمال عبد الرحمن عبد الحافظ، محمد معوض عبد المطلب قسم جراحة العظام، كلية الطب بنين، جامعة الأزهر

\section{البريد الإكتروني: dr.mahmoudali873@gmail.com}

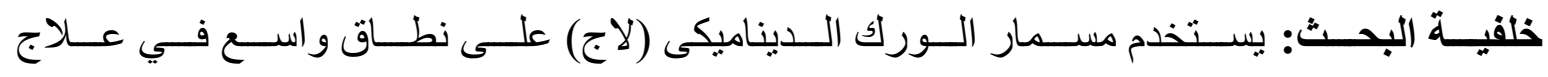

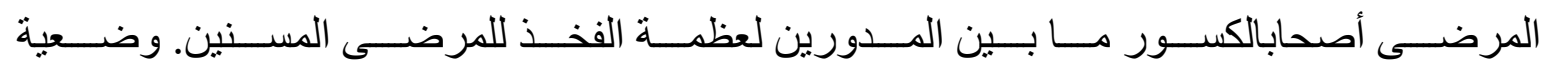

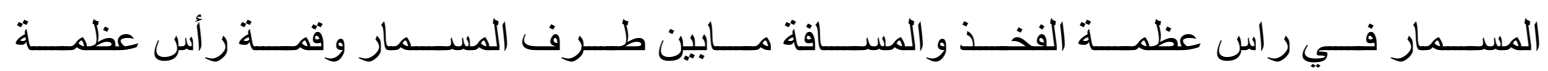
الفخذ في غاية الأهمية من أجل نجاح العملية.

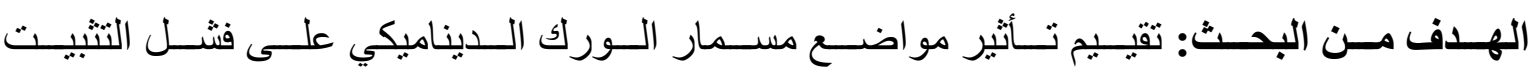

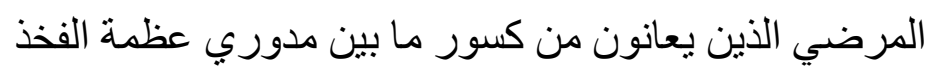

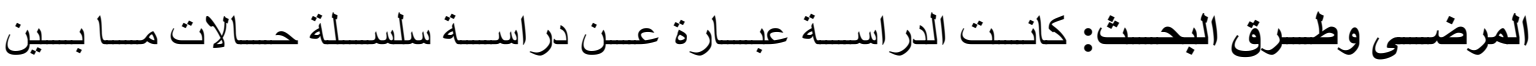

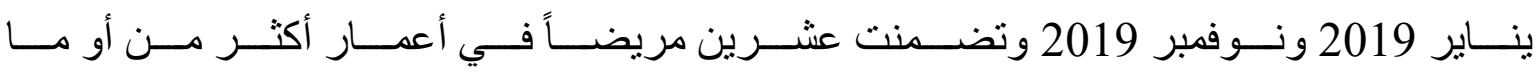

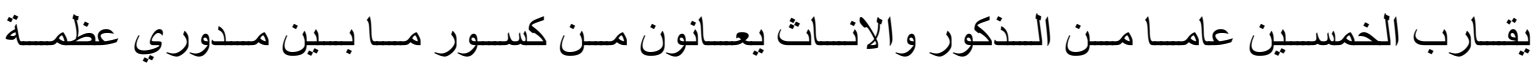

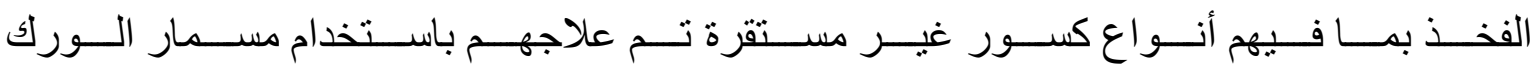

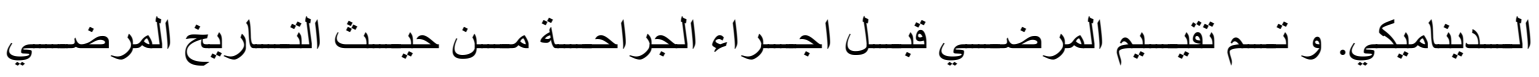

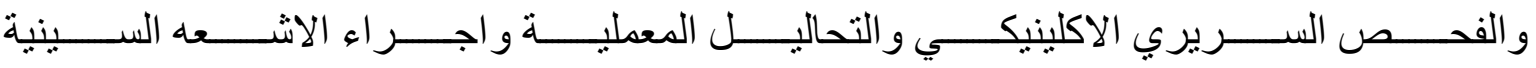

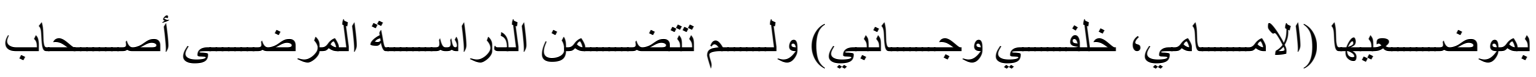

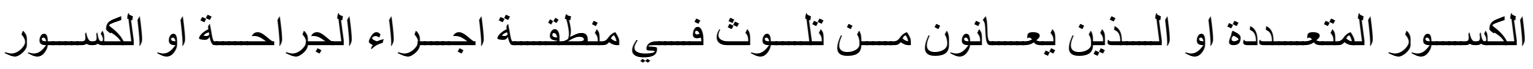
المرضية تجنبا لحدوث أية مضاعفات.

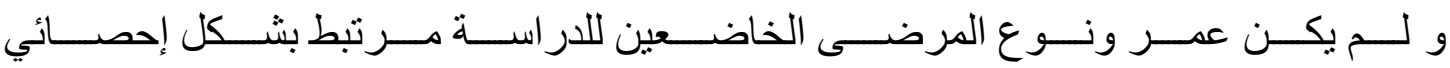

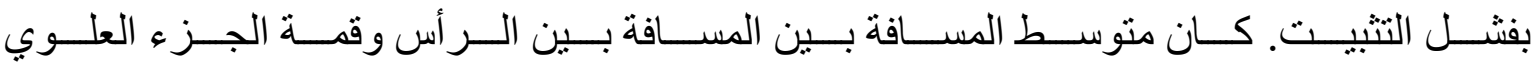

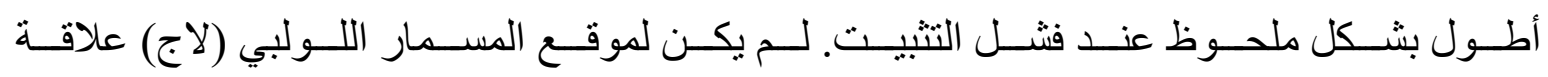

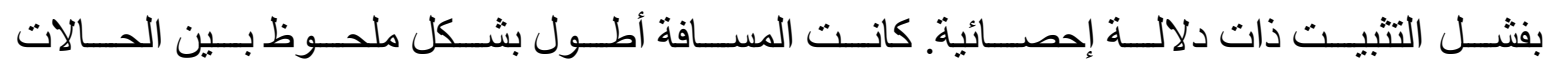

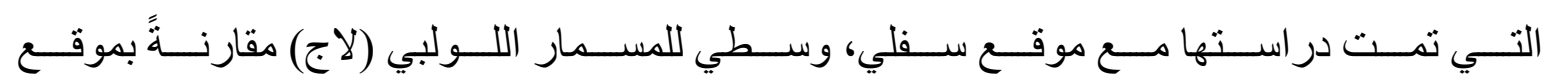
وسطي - وسطي للمسمار اللولبي (لاج). 


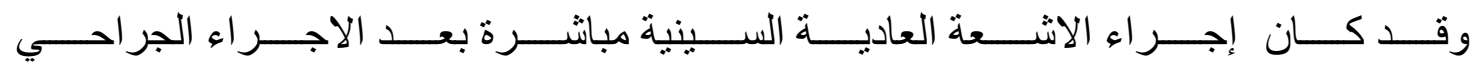

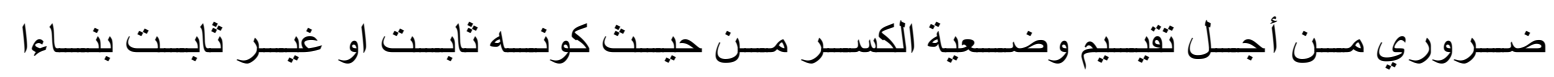

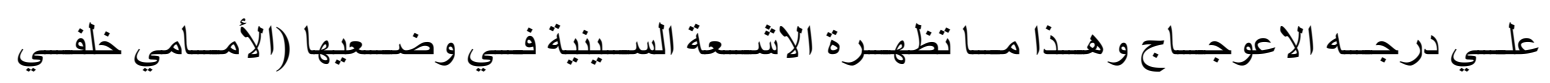
و الجانبي).

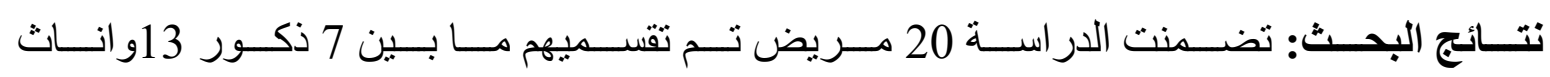

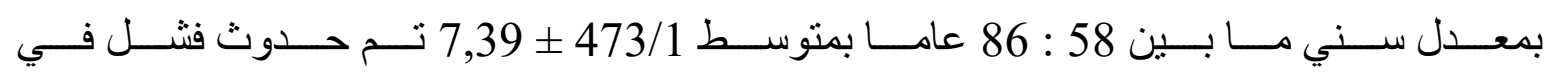

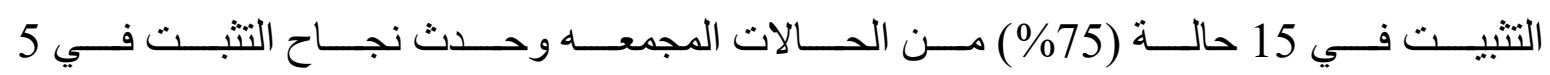
حالات (25 \% \%).

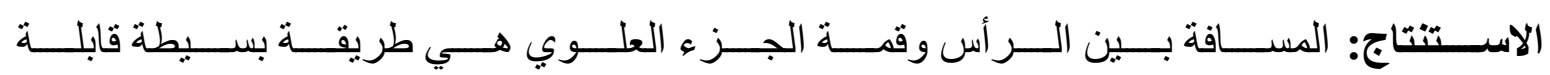

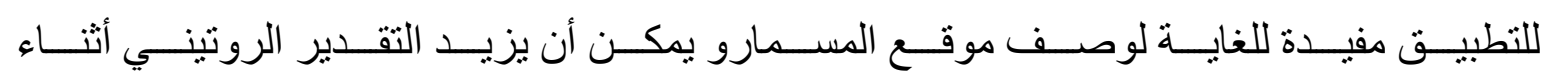

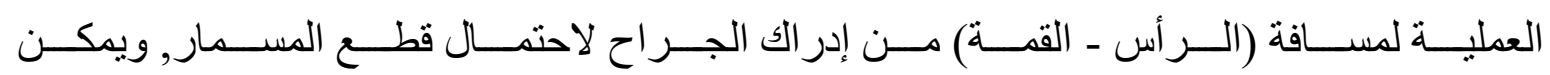

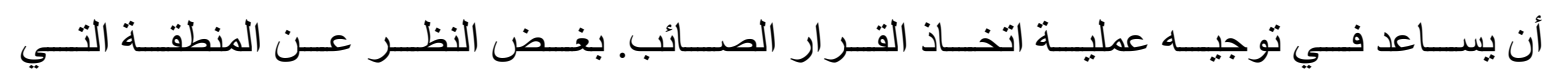

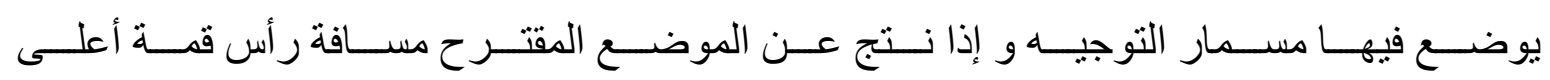

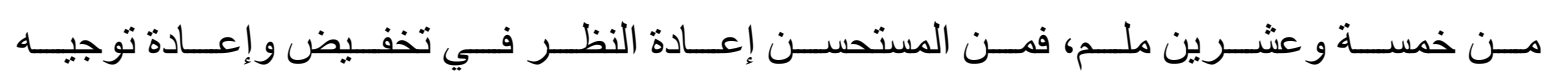
دبوس التوجيه.

الكلمــات الدالــة: كســور عظـــ الفخـذذ، مســـافة قمــة الــر أس، مســمار الــورك الــديناميكي، فثل التثبيت. 